Article

\title{
MV and LV Residential Grid Impact of Combined Slow and Fast Charging of Electric Vehicles
}

\author{
Niels Leemput ${ }^{1, *}$, Frederik Geth ${ }^{1}$, Juan Van Roy ${ }^{1}$, Pol Olivella-Rosell ${ }^{2}$, Johan Driesen ${ }^{1}$ and \\ Andreas Sumper ${ }^{2}$
}

1 Faculty of Engineering, Department of Electrical Engineering,

Division Electrical Energy \& Computer Architectures, KU Leuven, Kasteelpark Arenberg 10,

Box 2445, 3001 Leuven, Belgium; E-Mails: frederik.geth@gmail.com (F.G.);

juan.vanroy@esat.kuleuven.be (J.V.R.); johan.driesen@esat.kuleuven.be (J.D.)

2 Centre of Technological Innovation in Static Converters and Drives,

Department of Electrical Engineering, College of Industrial Engineering of Barcelona,

Universitat Politècnica de Catalunya-BarcelonaTech, Carrer Comte d'Urgell, 187-08036 Barcelona,

Spain; E-Mails: pol.olivella@ citcea.upc.edu (P.O.-R.); andreas.sumper@upc.edu (A.S.)

* Author to whom correspondence should be addressed; E-Mail: niels.leemput@gmail.com;

Tel.: +32-498-476-385.

Academic Editor: Paul Stewart

Received: 16 December 2014 / Accepted: 17 February 2015 / Published: 3 March 2015

\begin{abstract}
This article investigates the combined low voltage (LV) and medium voltage (MV) residential grid impact for slow and fast electric vehicle (EV) charging, for an increasing local penetration rate and for different residential slow charging strategies. A realistic case study for a Flemish urban distribution grid is used, for which three residential slow charging strategies are modeled: uncoordinated charging, residential off-peak charging, and EV-based peak shaving. For each slow charging strategy, the EV hosting capacity is determined, with and without the possibility of fast charging, while keeping the grid within its operating limits. The results show that the distribution grid impact is much less sensitive to the presence of fast charging compared to the slow charging strategy. EV-based peak shaving results in the lowest grid impact, allowing for the highest EV hosting capacity. Residential off-peak charging has the highest grid impact, due the load synchronization effect that occurs, resulting in the lowest EV hosting capacity. Therefore, the EV users should be incentivized to charge their EVs in a more grid-friendly
\end{abstract}


manner when the local EV penetration rate becomes significant, as this increases the EV hosting capacity much more than the presence of fast charging decreases it.

Keywords: electric vehicles; controlled charging; distribution grids; impact assessment

\section{Introduction}

Electric vehicles (EVs) are available on the market and their sales are growing. A primary difference with conventional vehicles is the way of refueling. EVs can charge at every location that offers a compatible electrical socket, of which the most common ones are at home and the workplace [1]. Due to the typically long standstill times at these locations, and the low average daily driven distances [2], a low charging power at these locations is sufficient to fulfill the majority of the mobility needs, thereby keeping the charging infrastructure investments low.

Typically, mode 2 or mode 3 charging, as defined in the IEC 61851-1 standard [3], are used to charge EVs at their standstill locations. Mode 2 charging makes use of a standard domestic socket, whereas mode 3 makes use of a dedicated grid connection. In Europe, single-phase charging is commonly rated at $10 \mathrm{~A}$ for mode 2 and $16 \mathrm{~A}$ for mode 3 [4]. As $90 \%$ of the daily EV energy consumption is below $18 \mathrm{kWh}$ [2], the daily charging time for mode 2 and mode 3 , respectively, remains below 9 and 6 h, $90 \%$ of time.

For occasional long-distance trips, fast charging is a necessary addition to slow charging, given the typical driving range of EVs nowadays. The implementation of fast charging networks that cover large contiguous regions make EVs a viable alternative for conventional vehicles [5,6]. The power rating for fast chargers vary from $50 \mathrm{~kW}$ [1] up to $120 \mathrm{~kW} \mathrm{[6],} \mathrm{which} \mathrm{allows} \mathrm{recharging} \mathrm{EVs} \mathrm{within} \mathrm{an}$ acceptable time span, typically within half an hour. Multistandard fast chargers provide compatibility with the different types of fast charging standards that are used nowadays [1].

EV charging will impact the power system, e.g., peak power demand, load profile and voltage magnitude deviations [7]. For slow charging, the residential low voltage (LV) grid impact may be significant, due to the simultaneity between the residential power peak and the plugging in of EVs when arriving at home, which starts the charging process for uncoordinated charging. Therefore, an extensive amount of research is conducted on coordinated slow charging strategies [8].

For fast charging, two typical infrastructure configurations are used. The first one is a network of single- or dual-outlet fast chargers that allow reaching the next fast charger. This is a configuration for the initial rollout of fast charging infrastructure [9]. The fast chargers are connected to the local LV grid, and therefore, the grid impact will strongly depend on the local situation, e.g., being connected to the distribution transformer through a separate feeder or through an existing feeder that contains other loads.

In the second configuration, fast charging stations with multiple fast chargers $(>4)$ are located next to busy traffic arteries. These stations resemble conventional highway refueling stations in their setup, and are typically commercially operated [1]. Because the total power rating of such stations is in the order of magnitude of a typical European residential LV grid ( $>200 \mathrm{kVA}$ ), they are connected to the medium voltage (MV) grid through a dedicated transformer. 


\subsection{Literature Overview}

\subsubsection{Slow Charging}

Different large-scale coordination objectives have been considered for mode 2 and mode 3 EV charging, e.g., integrating a higher share of intermittent renewable energy in the power system [10-12], congestion management [13], frequency regulation [14], portfolio imbalance reduction [15], charging cost minimization [16-18]. Large-scale coordinated charging shows to be effective to obtain such objectives. However, fast charging is not taken into account in their coordination strategies. Because the large-scale strategies require a substantial high EV penetration rate for the benefits to be noticeable [19], widespread coordinated charging is not expected soon. However, EV clusters may occur soon, which significantly impact the distribution grid.

EV charging can be controlled locally to smoothen the power profile of the distribution system [7], e.g., distribution grid peak shaving as explicit objective [20-22], or as a constraint in cost-minimizing coordination strategies [23,24]. Distribution grid peak shaving can be chosen as an optimization objective, to mitigate local load peaks in the distribution grid. This reduces the simultaneity of household and EV power demand, which positively impacts voltage deviations [20] and grid losses [21]. Voltage deviation reduction can also be considered as a coordination objective during times of excessive deviations [7].

A wide range of programming techniques are used to implement optimized charging strategies, e.g., linear programming [24,25], sequential quadratic programming [7,26], dynamic programming [7,14], convex quadratic programming [21], and heuristic programming [11,27]. The choice of the programming technique is a trade-off between optimality, completeness, accuracy, robustness, and execution time. Because no optimization model will be used here to represent control decision, but rather a set of rules, a further analysis of the different techniques is out of scope.

All of the above mentioned charging optimization strategies require communication between the grid and the EVs. Therefore, such strategies are ineffective in case of malicious or absent communication. To overcome this problem, local parameters can be used for a rule-based control of the EV charging process, opposed to the abovementioned optimization strategies. For example, the EV charging power rating can be reduced based on the required charging energy, which can be calculated by the EV itself based on the time until the next departure, which can be delivered as an input by the EV user. This concept is hereafter referred to as EV-based peak shaving. In previous work, this rule-based charging strategy has been investigated for one LV distribution grid [28]. In the considered grid, EV-based peak shaving allowed for a higher EV hosting capacity compared to other strategies. Fast charging was not included there.

\subsubsection{Fast Charging}

Several aspects of fast charging are investigated in the literature: economic assessments, infrastructure usage optimization, MV grid impact assessments, and the power electronic converter design. An economic analysis on fast charging infrastructure is performed for Germany [29] and China [30]. For both countries, it is concluded that fast charging infrastructure is hardly profitable with the present energy pricing and battery costs, and a high EV penetration rate is required for a profitable 
exploitation [29]. Both [29] and [30] do not use a time-based fast charging scenario in their modeling, as this is not the scope of an economic analysis.

Traffic modeling is used to determine the fast charging demand in space and time in [31]. The optimization of EV charging scheduling for highway fast chargers is discussed in [32] and [33]. The time-based occupation of the fast charging stations, and the variation of the EV battery state of charge at the start of the highway trip are based on a mathematical distribution, not on mobility behavior or slow charging behavior.

The MV grid impact of fast charging stations is discussed in [34-36]. A static worst-case load scenario is modeled in [34], assuming all fast chargers are used simultaneously at their rated power. Time-based vehicle arrival pattern of conventional refueling stations are used in [35], and time-based road occupation profiles are used in [36], to model the demand for fast charging. No slow charging behavior is taken into account, and in [35] and [36] it is assumed that the EVs continuously draw the rated fast charging power. Three-phase balanced loads are assumed in the MV grid, thereby not taking into account phase unbalance.

The electric and power electronic design of fast chargers is discussed in [37] and [38]. As these components need to be sized for the peak load, a worst-case scenario for the fast charging demand is used. The design of a fast charging station with local energy storage and local photovoltaic power production is discussed in [39]. The fast charging demand is based upon mobility behavior and takes into account residential slow charging. Load flow is not assessed, because the scope is on the sizing of the fast charging station and the power flow between its components.

\subsection{Scope}

To the best of the authors' knowledge, neither the combination of slow and fast charging, nor the combined MV and LV grid impact assessment is investigated in the literature. Both slow and fast charging behavior are modeled here, because they influence each other, and therefore, their interaction influences the grid impact. Grid impact is assessed for MV and LV, as both network levels influence each other.

A realistic Flemish distribution grid topology and a scenario realistic for the Flemish situation, are used here. Realistic single-phase Flemish household LV load profiles and measured photovoltaic (PV) power production profiles are used. The EV charging behavior is based upon Flemish mobility behavior and passenger vehicle fleet composition.

Three residential slow charging strategies are compared in terms of their EV hosting capacity, with and without the presence of fast charging. Fast charging is modeled to supplement slow charging at home and the workplace, when the battery capacity is insufficient to fulfill the mobility requirements otherwise. The fast charging infrastructure is assumed to consist out of charging stations with multiple fast chargers, sized to fulfill the fast charging demands of the area it covers. The fast charging stations are connected to the MV grid through a dedicated transformer. 


\section{Materials and Methods}

\subsection{Distribution Grid}

Three feeders are used to model three residential LV grid topologies, as illustrated in Figure 1 and with the parameters summarized in Table 1. These feeders are provided by the Flemish distribution system operators (DSOs) and are identified as (semi-) urban topologies, with a TT (Terra-Terra) grounding arrangement [40]. Cable parameters are taken from the design specifications of the cable standard NBN C33-322 [41]. All household loads $h$ are assumed to have a single-phase grid connection between one of the three phases $(p \in\{a, b, c\})$ and the common neutral conductor $(n)$, through feeder branching from the main one. The houses are connected alternatingly to each of the three phases. The rated neutral-to-phase voltage $U^{\text {nom }}$ is $230 \mathrm{~V}$.
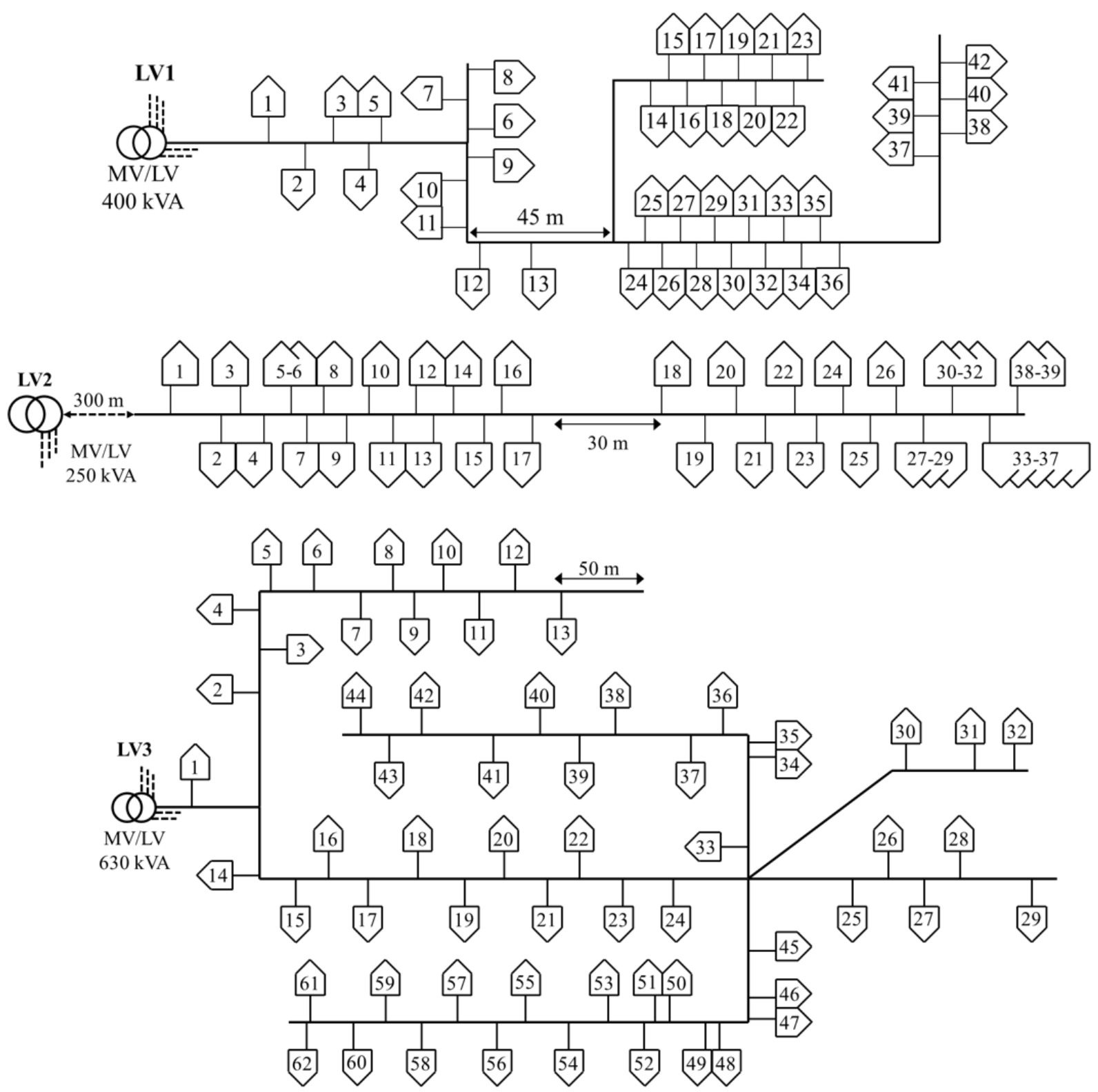

Figure 1. LV grid topologies. 
Table 1. LV grid parameters.

\begin{tabular}{|c|c|c|c|c|}
\hline \multicolumn{2}{|c|}{ Grid } & LV1 & LV2 & LV3 \\
\hline Cable type & $\begin{array}{l}\text { Primary } \\
\text { Secondary }\end{array}$ & $\mathrm{Cu}-4 \times 16 \mathrm{~mm}^{2}\left(35 \mathrm{~mm}^{2}\right.$ at 2 th last node LV2) & \multicolumn{2}{|c|}{$\mathrm{Al}-4 \times 150 \mathrm{~mm}^{2}$} \\
\hline $\boldsymbol{I}_{\mathrm{MAX}}[\mathbf{A}]$ & $\begin{array}{c}\text { Primary } \\
\text { Secondary }\end{array}$ & 245 & \multicolumn{2}{|l|}{$120(175)$} \\
\hline$Z[\mathbf{\Omega} / \mathbf{k m}]$ & $\begin{array}{c}\text { Primary } \\
\text { Secondary }\end{array}$ & $\begin{array}{r}0.320+0.078 i \\
1.15+\end{array}$ & \multicolumn{2}{|c|}{$\begin{array}{r}0.206+0.078 i \\
(0.524+0.081 i)\end{array}$} \\
\hline \multicolumn{2}{|c|}{$\begin{array}{l}\text { \# nodes/feeder } \\
\text { \# loads/feeder }\end{array}$} & $\begin{array}{l}42 \\
42 \\
\end{array}$ & $\begin{array}{l}29 \\
39 \\
\end{array}$ & $\begin{array}{l}62 \\
62 \\
\end{array}$ \\
\hline Parallel feeders & $\begin{array}{c}\text { \# Added feeders } \\
\text { Length [m] }\end{array}$ & $\begin{array}{c}5 \\
250 \\
\end{array}$ & $\begin{array}{c}3 \\
250 \\
\end{array}$ & $\begin{array}{c}5 \\
300 \\
\end{array}$ \\
\hline \multicolumn{2}{|c|}{$\begin{array}{c}\text { Total \# LV loads } \\
Z \text { transformer }[\Omega]\end{array}$} & $\begin{array}{c}252 \\
0.008+0.029 i \\
\end{array}$ & $\begin{array}{c}156 \\
0.013+0.045 i \\
\end{array}$ & $\begin{array}{c}372 \\
0.004+0.020 i\end{array}$ \\
\hline
\end{tabular}

The three feeders are connected to three different MV/LV transformers (Delta-Wye+N), which have three commonly occurring power ratings for Flanders: 250, 400, and $630 \mathrm{kVA}$. The transformer impedances are derived from [42], and their taps are set at $1 \mathrm{pu}$. A higher transformer tap could be selected to increase the lowest occurring voltages, which would reduce the impact of the EV charging load on the voltage deviations. However, this would also increase the highest occurring voltages, as no on-load tap changers are used at MV/LV transformers in Flanders. This can cause overvoltage events, at moments of high residential PV production, as residential PV power production reduces the operational margins [43]. Therefore, the taps are chosen at 1 pu here, as the goal is not to find the optimal tap settings, but to provide a realistic scenario for a Flemish distribution grid with PV power generation. Different tap settings would obviously influence the results, but the qualitative results of the comparative analysis of the different charging strategies would remain the same, as the tap settings remain fixed during this analysis.

Because multiple LV feeders are connected to each MV/LV transformer, a number of simplified parallel feeders, as summarized in Table 2, are added to each of the three grid topologies, as in [29]. An aggregated load, with an equivalent number of households as for each of the three detailed feeders, is added to the end of each parallel feeder. The three LV grid topologies are each used three times, together with the fast charging station (FCS), to connect to a MV feeder with 9 nodes, as illustrated in Figure 2. As a result, a total of 2340 household loads are connected to the MV feeder. The rated MV line-to-line voltage is $11 \mathrm{kV}$, and the distance between each node is $600 \mathrm{~m}$. This is a realistic urban MV feeder topology for Flanders [44], where MV grids are operated in an open-ring topology with few or absent laterals [45]. The MV cable is a three-core armored aluminum conductor, i.e., Al $11 \mathrm{kV}-3 \times 95 \mathrm{~mm}^{2}$, with an impedance of $0.411+0.105 i \Omega / \mathrm{km}$, and a current rating of $200 \mathrm{~A}$ [46].

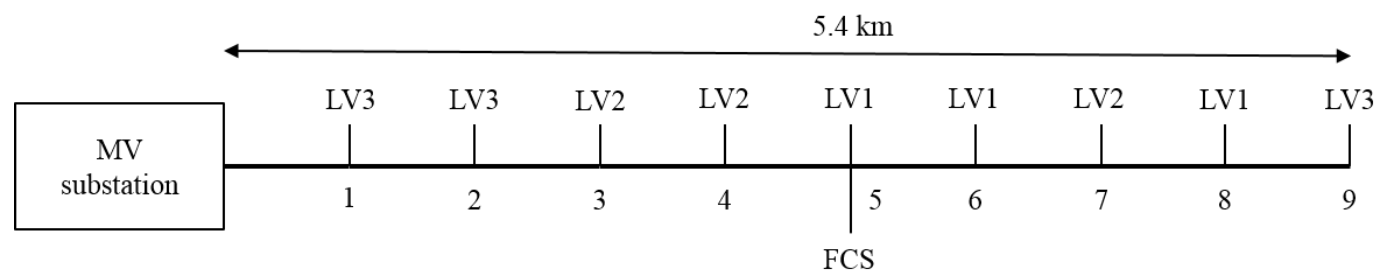

Figure 2. MV grid topology to which the LV grids and the fast charge station (FCS) are connected. 
Table 2. LV feeder locations of the randomly assigned PV installations.

\begin{tabular}{cc}
\hline MV Node & Houses with a PV Installation \\
\hline 1 & $1,17,21,24,42,46,50$ \\
2 & $6,15,20,27,43,57,58$ \\
3 & $10,16,17,23$ \\
4 & $10,17,20,25$ \\
5 & $1,6,17,21,37$ \\
6 & $3,26,28,30,42$ \\
7 & $9,21,25,31$ \\
8 & $2,8,22,27,33$ \\
9 & $6,7,18,23,37,49,58$ \\
\hline
\end{tabular}

The end-user distribution grid voltages should stay within the operation limits of the EN50160 standard [47], which are defined as follows:

$$
\begin{gathered}
0.9 \cdot U^{\mathrm{nom}} \leq\left|U_{p, i, k}\right| \leq 1.1 \cdot U^{\mathrm{nom}}, \\
\text { for }>95 \% \text { of all } 10 \mathrm{~min} \text { intervals of any week } \\
0.85 \cdot U^{\mathrm{nom}} \leq\left|U_{p, i, k}\right| \leq 1.1 \cdot U^{\mathrm{nom}}, \\
F_{i, k}^{\mathrm{VU}} \leq 2 \%, \text { for }>95 \% \text { of all } 10 \text { min intervals of any week }
\end{gathered}
$$

$U^{\mathrm{nom}}$ is the nominal voltage magnitude, i.e., $230 \mathrm{~V} .\left|U_{p, i, k}\right|$ and $F_{i, k}^{\mathrm{VU}}$ are, respectively, the voltage rms magnitude and the voltage unbalance factor at phase $p$, grid node $i$, and time step $k$.

These voltage magnitude and unbalance constraints, together with the above mentioned feeder current constraints, will determine how much EV charging load the distribution grid can accept, additional to the residential load and the PV power generation. As a result, these constraints will determine the EV hosting capacity. Opposed to the current and voltage constraints, the transformer power rating is not a hard real-time constraint. Exceeding the transformer power rating accelerates its ageing, which reduces the technical lifetime of the transformer. If this technical lifetime goes below the economic lifetime, the transformer will need to be replaced earlier than initially expected. This is a cost that should be taken into account, but it does not require immediate action.

\subsection{Residential Load and PV Generation}

A residential electric load profile generator is used to create a statistically representative set $H_{o}$ of single-phase Flemish household electric power consumption profiles $h$, with a 15 min time resolution, as presented in [48]. Variations between week and weekend days, as well as seasonal variations, are taken into account in the profiles. Reactive power consumption is neglected, because this is not generated by the profile generator. This is because residential grid-connected PV power generation amounts to $10 \%$ of the residential power consumption in Flanders [49]. Therefore, a PV installation is randomly assigned to $10 \%$ of the houses. The random assignment of the PV installation locations on the detailed feeders, as summarized in Table 2, is done to take into account the locational sensitivity of their grid impact.

The PV power profiles are based upon full-year measurements on an installation at the KU Leuven, with a 15 min time resolution. Therefore, seasonal variations in PV power generation are taken into 
account. The profiles are scaled to match the annual energy generation to the annual energy consumption at the selected household, taking into account the single-phase regulatory inverter power rating limit of $5 \mathrm{kVA}$ in Flanders [50]. A power factor (PF) of 1 is assumed for the inverter [51].

\subsection{EV Charging Load}

A mobility profile generator is used to create a representative Flemish set $\varepsilon_{0}$ of EV charging profiles $e$ ( 1 vehicle per household $=100 \% \mathrm{EV}$ penetration rate) with a $1 \mathrm{~min}$ time resolution $T_{s}$. The model is explained in detail in [29], and consists of three sub-models: (1) a mobility behavior model; (2) a battery energy storage model; and (3) a charge behavior model.

The mobility profile of each EV is created with the mobility simulation tool that is discussed in [52]. This tool uses statistical data on Flemish transportation behavior, to create realistic driving patterns. For each vehicle, it is known when it is driving, standing still, and also where it is standing still: at home, at the workplace, or at other locations. In this model, the difference in mobility behavior during weekdays and weekend days is included. Seasonal variations are not taken into account, because for Flanders, no useful data is available on such variations.

The diversity of vehicle types and vehicle fuels within the fleet, and the resulting variations in specific power consumption and yearly driven distances are taken into account. The fleet consists out of three vehicle types: subcompact, midsize, and large vehicles. The vehicle types are modeled, based upon two vehicles within that category. The type-specific parameters are summarized in Table 3 for the modeled vehicles. Other parameters remain identical for all the vehicle type, e.g., the tire rolling resistance factor (0.01) and the auxiliary power consumption $(500 \mathrm{~W})$. A detailed explanation, including all assumptions, parameters, and drive cycles, can be found in [52]. The resulting fleet consists out 945 subcompact (40.4\%), 1124 midsize (48\%) and 271 large vehicles (11.6\%).

Table 3. Summary of the parameters for the vehicle types [52].

\begin{tabular}{ccccc}
\hline \multirow{2}{*}{ Vehicle model } & Mass $[\mathbf{k g}]$ & Frontal Surface $\left[\mathbf{m}^{2}\right]$ & $\boldsymbol{C}_{\boldsymbol{X}}$ \\
\hline \multirow{2}{*}{ Subcompact } & Mistubishi $i$-MiEV & 1100 & 2.37 & 0.33 \\
& Smart Electric Drive & 975 & 2.40 & 0.35 \\
\hline \multirow{2}{*}{ Midsize } & Nissan Leaf & 1521 & 2.70 & 0.28 \\
& Chevrolet Volt & 1800 & 2.55 & 0.28 \\
\hline \multirow{2}{*}{ Large } & Toyota RAV4 EV & 2000 & 3.10 & 0.33 \\
& eRUF Cayenne & 2670 & 3.30 & 0.36 \\
\hline
\end{tabular}

The resulting specific power consumption for each vehicle category is, respectively, $0.181,0.213$ and $0.302 \mathrm{kWh} / \mathrm{km}$. The differences are significant, due to the differences in vehicle weight and air resistance. Given the average vehicle speed in Flanders of $42 \mathrm{~km} / \mathrm{h}$, the average battery discharging power $P_{k}^{d}$ for each vehicle category is, respectively, 7.6, 8.9, and $12.7 \mathrm{~kW}$, during driving.

The battery energy storage model, as discussed in detail in [53], is used to calculate the evolution of the battery energy content $E_{k}$ and the state of charge $S O C_{k}$ during each one-minute time step of the one-week simulation as specified in Section $2.5(k \in\{1,2, \ldots, 10080\})$ :

$$
E_{k}=E_{k-1}-\delta_{k}^{\mathrm{sd}}+\left(\eta^{\mathrm{ch}} T_{s} P_{k}^{\mathrm{ch}}-T_{s} P_{k}^{\mathrm{d}} / \eta^{\mathrm{d}}\right)
$$




$$
S O C_{k}=100 \cdot E_{k} / E^{\mathrm{nom}}
$$

The self-discharge $\delta_{k}^{\text {sd }}$ is equal to $3 \%$ of the rated battery capacity $E^{\text {nom }}$ per month, which is 20,30 , and $40 \mathrm{kWh}$ for the three vehicle types, respectively. $P_{k}^{\mathrm{ch}}$ and $P_{k}^{\mathrm{d}}$ are the charging and discharging power during each time step $k$. Both Equations (4) and (5) are valid for all time steps of the simulation, as they are both applicable during driving and during standstill. Obviously, an EV cannot be simultaneously charging and discharging $\left(P_{k}^{\mathrm{ch}} \cdot P_{k}^{\mathrm{d}}=0\right)$, as an EV cannot be grid connected and driving at the same time. Therefore, during driving $P_{k}^{\mathrm{ch}}=0$, and during standstill $P_{k}^{\mathrm{d}}=0$. Furthermore, when an EV is not grid connected during standstill or when the battery is already fully charged, then also $P_{k}^{\text {ch }}=0$. The charging and discharging efficiencies $\eta^{\text {ch }}$ and $\eta^{\mathrm{d}}$ are $90.25 \%$, which includes the electrochemical $(95 \%)$ and the power electronic $(95 \%)$ conversion efficiencies. The battery is never discharged below $20 \%$ SOC, to extend the battery cycle life [54].

The EVs are grid-connected at home and at the workplace, whenever they are standing still for more than 15 min. For shorter standstill times, it is assumed that the EV user will not make the effort to connect the EV to the charging infrastructure, because of the limited SOC increase during such a short time span. Mode 3 charging is assumed at these locations [3], with the commonly occurring single-phase charging power rating $P^{\mathrm{ch}}$ of $3.3 \mathrm{~kW}$, which results in a current of $16 \mathrm{~A}$ at $90 \%$ of $U_{\text {nom }}$ in continental Europe [4]. The end-of-charge power limit $P^{\mathrm{EOC}}\left(\operatorname{SOC}_{k}\right)$, as illustrated in Figure 3, is based upon measurements performed on real vehicles, as discussed in [54]. When the SOC exceeds $92 \%$, $P^{\mathrm{EOC}}\left(S O C_{k}\right)$ will limit the effective charging to below $P^{\mathrm{ch}}$.
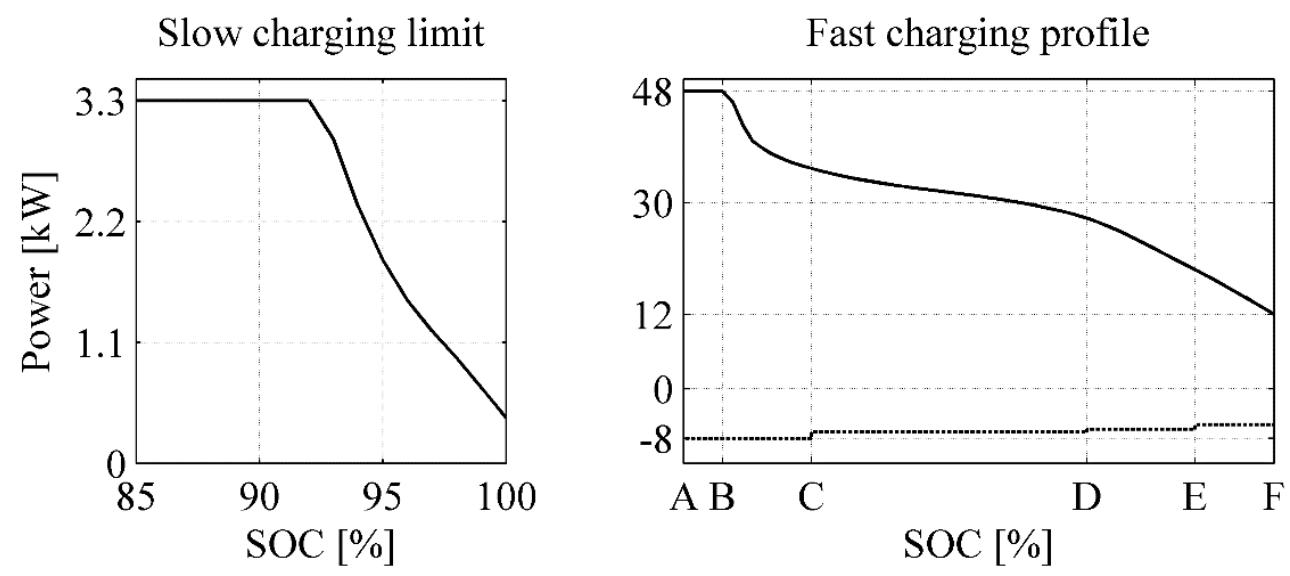

Figure 3. (left) charging power limit for slow charging; and (right) active (solid line) and reactive (dashed line) power profile for fast charging.

The fast charging demand is modeled as discussed in [40]: the EVs will interrupt their trip if the SOC goes below the threshold value SOC $(t h)$, which is chosen uniformly between $20 \%$ and $30 \%$ for each trip: $\operatorname{SOC}(t h) \epsilon\{20 \% \ldots 30 \%\}$. This is to take into account that an EV will not be exactly located at a fast charging station when the SOC reaches the $20 \%$ limit, as discussed above. When fast charging occurs, it is assumed that the battery will be fast charged up to $80 \%$ SOC. The fast charging power profile $P^{\mathrm{FC}}\left(S O C_{k}\right)$, as illustrated in Figure 3, is based upon measurements that are discussed in [55]. Point A and point F coincide with $\operatorname{SOC}(t h)$ and point $80 \%$, respectively. As a result, depending on $\operatorname{SOC}(t h)$, points B to E occur at a different SOC values. The calculation of these points is summarized in Table 4. As can be seen, the fast chargers inject reactive power $Q^{\mathrm{FC}}$ into the grid, which are included 
in the simulations. The reactive power injection reduces in 4 discrete steps, as a function of the active fast charging power that is drawn. This behavior is implemented in the fast charger by the manufacturer as a way to reduce the voltage drop induced by the fast charger, i.e., phase leading behavior.

Table 4. Calculation of the SOC values for the fast charging profile.

\begin{tabular}{cc}
\hline Point & SOC Value \\
\hline $\mathrm{A}$ & $\operatorname{SOC}(t h)$ \\
$\mathrm{B}$ & $\operatorname{SOC}(t h)+((\operatorname{SOC}(F)-S O C(t h)) \cdot(1 / 15))$ \\
$\mathrm{C}$ & $\operatorname{SOC}(t h)+((\operatorname{SOC}(F)-S O C(t h)) \cdot(1 / 5))$ \\
$\mathrm{D}$ & $\operatorname{SOC}(t h)+((\operatorname{SOC}(F)-\operatorname{SOC}(t h)) \cdot(2 / 3))$ \\
$\mathrm{E}$ & $\operatorname{SOC}(t h)+((\operatorname{SOC}(F)-\operatorname{SOC}(t h)) \cdot(5 / 6))$ \\
$\mathrm{F}$ & $80 \%$ \\
\hline
\end{tabular}

\subsection{Slow Charging Cases}

Slow charging occurs in all cases $c$, which are summarized in Table 5 and are compared to the case without EVs, i.e., case 0. Each case is simulated (a) without and (b) with fast charging. The EVs are modeled as extended range electric vehicles, in which the combustion engine is only engaged when the battery is depleted. Therefore, even if the battery is depleted in the cases without fast charging, all mobility requirements are met. Three slow charging strategies are modeled, which represent three typical charging objectives: high comfort, low charging cost, and low grid impact. Further assessments and more advanced charging strategies could be considered, but this is out of scope for this article.

Table 5. Summary of the slow charging cases.

\begin{tabular}{cc}
\hline Case $c$ & Description \\
\hline 0 & No EVs \\
$1 \mathrm{a}$ & Uncoordinated charging without fast charging \\
$1 \mathrm{~b}$ & Uncoordinated charging with fast charging \\
$2 \mathrm{a}$ & Off-peak charging without fast charging \\
$2 \mathrm{~b}$ & Off-peak charging with fast charging \\
$3 \mathrm{a}$ & EV-based peak shaving without fast charging \\
$3 \mathrm{~b}$ & EV-based peak shaving with fast charging \\
\hline
\end{tabular}

For $c=1$, the objective is to maximize the user's comfort. Each EV immediately starts charging when it is grid-connected at home and at the workplace. The charging power set point for case $1 P_{k, 1}^{\text {set }}$ is equal to the rated Mode 3 charging power $P^{\mathrm{ch}}$, i.e., $3.3 \mathrm{~kW}$ :

$$
P_{k, 1}^{\text {set }}=P^{\mathrm{ch}}
$$

For $c=2$, the objective is to decrease the residential charging cost. Therefore, the EVs only charge at home during the off-peak tariff period, when the end user electricity price is about $30 \%$ lower than during the on-peak tariff period in Flanders [56]. This tariff occurs when the time of day $T_{k}$ is between $10 \mathrm{pm}$ and $7 \mathrm{am}$ :

$$
P_{k, 2}^{\text {set }}=\left\{\begin{array}{r}
P^{\mathrm{ch}}, 10 \mathrm{pm} \leq T_{k} \leq 7 \mathrm{am} \\
0,7 \mathrm{am}<T_{k}<10 \mathrm{pm}
\end{array}\right.
$$


At the workplace, the EVs will still be able to charge between 7 am and $10 \mathrm{pm}$, because the charging cost at the workplace might be significantly different from the one at home. This rule-based strategy only makes use of the time of day $\left(T_{k}\right)$, which is known by the onboard computer.

For $c=3$, the objective is to reduce the local grid impact with a strategy that can be implemented without interaction between the end user and the grid. EV-based peak shaving, a rule-based strategy as explained in detail in [29], is used: the nominal set point $P_{k, 3}^{\text {set,nom }}$ is the minimum power rating required to get the battery charged in the time span until the next departure $\Delta T^{\text {dep }}$, taking into account the upper limit of $P^{\mathrm{ch}}$ and the end-of-charge power limitation $P^{\mathrm{EOC}}\left(S O C_{k}\right)$ :

$$
P_{k, 3}^{\text {set }}=f\left(E^{\mathrm{nom}}, E_{k}, \Delta T^{\mathrm{dep}}, P^{\mathrm{ch}}, P^{\mathrm{EOC}}\left(\operatorname{SOC}_{k}\right)\right)
$$

As a result, the battery charged to the same level at the departure time as with case 1 . This charging strategy makes use of one user input: the next departure time. The other parameters are already available in the onboard computer.

For all cases, the end of charge behavior limits the effective charging power $P_{k, c}^{\text {ch }}$ at SOC values above $92 \%$ :

$$
P_{k, c}^{\mathrm{ch}}=\left\{\begin{array}{r}
P_{k, j}^{\mathrm{set}}, S O C_{k} \leq 92 \% \\
P^{\mathrm{EOC}}\left(S O C_{k}\right), S O C_{k}>92 \%
\end{array}\right.
$$

Neither one of the three charging cases makes use of an optimization strategy. For $c=1$, the charging behavior is directly determined by the mobility behavior. For $c=2 / 3$, the charging behavior is controlled by a rule-based strategy that makes use of onboard parameters, and an additional user input for $c=2$.

\subsection{Simulation Approach}

The simulations are conducted for a one-week scenario, resulting in a number of time steps $n_{t}=10,080$, i.e., $k \in\left\{1,2, \ldots, n_{t}\right\}$. The one-week scenario is conducted for a week that is representative for the first quarter of the year, because this is the period of the year when high grid loads occur in Flanders. Therefore, the grid constraints will be exceeded the soonest when additional load, due to EV charging, is added. The simulations are conducted for an EV penetration rate that increases in steps of $10 \%$ until $100 \%$, or until the load flow offers no feasible solution. The LV feeder locations of the vehicles that are added for each step are summarized in Table 6. As can be seen, the location is diversified, to take into account the locational sensitivity of the results.

For each $1 \mathrm{~min}$ time step $T_{s}$, the evolution of the SOC of the EVs is calculated as formulated in Equations (4) and (5). The resulting residential EV charging profile is added to the residential load and generation profile at the respective LV grid nodes. The residential load and generation profiles are kept constant for their $15 \mathrm{~min}$ period. The aggregated fast charging load is added to the 5 th node on the MV grid through a separate MV/LV transformer, as illustrated in Figure 2. The workplace charging profiles are not added, as it is assumed that there are no workplace charging locations in this residential grid.

To obtain grid impact results as discussed in Section 3.3-3.5, a three-phase unbalanced load flow algorithm is implemented in MATLAB. Unbalanced loads are taken into account, as well as the resulting LV neutral conductor voltage drop. The backward-forward sweep technique is used, because of the radial layout of the grid [57]. The problem is converged when the worst time step voltage error 
$\mathrm{eV}$ is below $0.1 \mathrm{~V}$. All loads are modeled as constant power loads with unity power factor, except for the fast chargers, which will inject a reactive power $P^{\mathrm{FC}}\left(S O C_{k}\right)$ during fast charging, as illustrated in Figure 3.

For each charging case, the EV hosting capacity is calculated, which is the highest EV penetration rate that can be achieved without exceeding the feeder current constraints and the grid voltage constraints, as discussed in Section 2.1.

Table 6. Location (house number) of the EVs on the LV feeders.

\begin{tabular}{cccccccccc}
\hline \multirow{2}{*}{$\begin{array}{c}\text { EV } \\
\text { Group }\end{array}$} & $\mathbf{1}$ & $\mathbf{2}$ & $\mathbf{3}$ & $\mathbf{4}$ & $\mathbf{5}$ & $\mathbf{6}$ & $\mathbf{7}$ & $\mathbf{8}$ & $\mathbf{9}$ \\
\cline { 2 - 10 } \multirow{2}{*}{$\mathbf{1 0 \%}$} & $4,7,13$, & $10,17,31$, & 4,25, & 4,7, & $10,11,13$, & $6,11,14$, & 22,25, & 2,11, & $3,6,8,10$, \\
& $16,27,37,54$ & $33,44,58,60$ & 27,37 & 8,30 & 24,50 & 28,38 & 28,38 & 18,33 & $20,22,23$ \\
\hline \multirow{2}{*}{$\mathbf{2 0 \%}$} & $10,15,41$, & $14,32,41$, & 3,7, & 6,17, & 8,25, & 1,3, & 7,17, & 5,13, & $7,27,32$, \\
& $44,46,57$ & $43,46,53$ & 14,22 & 18,35 & 27,42 & 19,30 & 34,37 & 19,42 & $40,52,55$ \\
\hline \multirow{2}{*}{$\mathbf{3 0 \%}$} & $6,11,12$, & $16,24,27$, & 16,19, & 3,5, & 12,15, & 7,12, & 1,14, & 24,26, & $17,33,41$, \\
& $34,35,51$ & $35,45,49$ & 33,39 & 28,38 & 38,39 & 32,33 & 30,32 & 30,32 & $43,46,62$ \\
\hline \multirow{2}{*}{$\mathbf{4 0 \%}$} & $18,21,30$, & $13,37,42$, & 2,11, & 15,20, & 4,6, & 5,8, & 6,13, & 7,20, & $21,24,43$, \\
& $40,43,61$ & $51,56,62$ & 21,23 & 25,29 & 7,41 & 9,39 & 19,29 & 36,40 & $49,53,60$ \\
\hline \multirow{2}{*}{$\mathbf{5 0 \%}$} & $20,36,39$, & $3,8,28$, & 1,15, & 1,13, & 9,16, & 2,16, & 3,8, & 15,35, & $2,9,14$, \\
& $52,53,56$ & $34,52,55$ & 17,31 & 19,32 & 18,34 & 18,29 & 21,26 & 39,41 & $26,37,56$ \\
\hline \multirow{2}{*}{$\mathbf{6 0 \%}$} & $2,19,23$, & $5,9,20,26$, & 10,24, & 21,27, & 14,22, & 10,15, & 24,27, & $4,8,9$, & $13,18,35$, \\
& $24,33,38,60$ & $29,50,61$ & 28,35 & 31,33 & $30,33,37$ & $23,27,41$ & 31,39 & 25,29 & $47,48,54,61$ \\
\hline \multirow{2}{*}{$\mathbf{7 0 \%}$} & $3,8,17$, & $18,21,36$, & 9,26, & 11,14, & 2,19, & 20,21, & 2,12, & 3,17, & $11,15,34$, \\
& $28,42,48$ & $38,47,59$ & 29,34 & 16,26 & 24,35 & 35,40 & 16,33 & 23,38 & $42,57,59$ \\
\hline \multirow{2}{*}{$\mathbf{8 0 \%}$} & $5,14,22$, & $2,6,7,12$, & 8,24, & 2,10, & 3,28, & 4,22, & 5,18, & 6,10, & $4,12,16$, \\
& $25,47,55$ & 48,57 & 28,37 & 36,39 & 31,32 & 26,36 & 20,35 & 27,34 & $29,45,58$ \\
\hline \multirow{2}{*}{$\mathbf{9 0 \%}$} & $1,31,32$, & $1,4,19,22$, & 5,6, & 12,22, & 1,16, & 13,25, & 4,11, & 12,16, & $1,19,25$, \\
& $45,50,59$ & 23,25 & 12,20 & 24,37 & 21,29 & 37,42 & 23,36 & 28,37 & $28,36,39$ \\
\hline \multirow{2}{*}{$\mathbf{1 0 0 \%}$} & $9,26,29$, & $11,15,30$, & 13,18, & 9,23, & 5,20, & 17,24, & 9,10, & 1,21, & $5,30,31$, \\
& $49,58,62$ & $39,40,54$ & 30 & 26 & 26,36 & 31,34 & 15 & 22,31 & $38,50,51$ \\
\hline \multirow{2}{*}{$\mathbf{2} 3}$,
\end{tabular}

\section{Results and Discussion}

\subsection{User Impact}

To assess the dependency of the EVs on their range extender for the cases without fast charging, the utility function $F^{\mathrm{U}}$ is defined as the ratio of the electrically driven distances to the total driven distances [58]. Obviously, $F^{\mathrm{U}}$ is $100 \%$ for each $\mathrm{EV}$ when fast charging is possible, given that the fast charging stations have a sufficient geographical spreading. For all cases without fast charging, the maximum $F^{\mathrm{U}}$ is $100 \%$, i.e., there is at least one vehicle in the fleet of $2340 \mathrm{EVs}$ that will drive purely electrically during the simulated week. For $c=1 a / 3 a$, the minimal and mean $F^{\mathrm{U}}$ are $84.2 \%$ and $96.7 \%$, respectively. The values are identical for both cases, because they provide the same SOC by the next departure time. For $c=2 a$, it has a marginally lower minimal and mean $F^{\mathrm{U}}$, namely $82.6 \%$ and $96.2 \%$, respectively. The difference compared to $c=1 a / 3 a$ is very small, because the charging time is usually well below the standstill time within the off-peak time span. 
The total required electric driving energy for the EVs is $170,636 \mathrm{kWh}$, for the fleet of $2340 \mathrm{EVs}$ during the one-week simulation period that is created here. This account for the energy being delivered by the EV batteries, by slow and fast charging for the b-cases, and by slow charging and the range extender for the a-cases. The share of charging energy for the different locations is summarized in Table 7. The majority of EV charging occurs at home, while workplace charging only accounts for $5.6 \%$ to $6.7 \%$ of the charging energy, due to the low average distance between home and the workplace. For $c=2$, the slightly higher share in workplace charging energy is due to the limitation of the charging time at home. Therefore, sometimes the EV is not fully charged when leaving home to go to work. As a result, more charging energy is delivered at the workplace.

Table 7. Share of charging energy for the different locations.

\begin{tabular}{ccccc}
\hline Case & $\mathbf{1 / 3 a}$ & $\mathbf{1 / 3 b}$ & $\mathbf{2 a}$ & $\mathbf{2 b}$ \\
\hline Home (slow) & 94.0 & 83.3 & 93.3 & 81.1 \\
Work (slow) & 6.0 & 5.6 & 6.7 & 6.0 \\
Fast & $/$ & 11.1 & $/$ & 12.9 \\
\hline
\end{tabular}

Fast charging delivers $11.1 \%$ up to $12.9 \%$ of the charging energy, depending on the slow charging case. The presence of fast charging mainly reduces the share of residential charging energy, as can be seen when comparing the shares of charging energy at home of the a-cases with the b-cases. The share of fast charging energy strongly depends on the assumptions being made. In theory, fast charging could be used to charge the batteries exactly up to the SOC that is required to reach the next charging destination, instead of charging up to $80 \%$ by default. Also, if the fast charging infrastructure would be perfectly spread out, each EV would reach a fast charge station when their battery SOC reaches the $20 \%$ threshold value. Under these theoretical assumptions, the share of fast charging energy would equal the share of energy being delivered by the range extenders for the cases without fast charging, i.e., $3.3 \%$ for $c=1 b / 3 b$, and $3.8 \%$ for $c=2 b$. Furthermore, larger battery capacities will also decrease the need for fast charging. For example, a doubling of the battery capacities decreases the share of fast charging energy to $2.3 \%$ for $c=1 b / 3 b$, and $3.2 \%$ for $c=2 b$.

\subsection{Charging Behavior}

As a detailed illustration of the difference in charging behavior between the different charging cases, the charging profile for a single EV is shown in Figure 4 for a $17 \mathrm{~h}$ timespan, for $c=1 b / 2 b / 3 b$. Also, the evolution of the SOC is shown. In this example, the fast charging profiles are identical for the three cases, but the residential charging profiles are different. The latter is similar in shape for $c=1 b$ and $c=2 b$, but shifted in time. For $c=1 b$, the charging process at home starts immediately when the EV arrives there (around $21.15 \mathrm{~h}$ ), while for $c=2 b$, the charging starts at 22:00, when the off-peak tariff period starts. For $c=3 b$, the charging also starts immediately when arriving at home, but with charging power significantly reduced, because in this example, there is a long standstill time at home before the next departure (more than $15 \mathrm{~h}$ until the next departure). As a result, the SOC rises more slowly for $c=3 b$, compared to $c=1 b / 2 b$. This clearly illustrates how the slow charging profiles are significantly affected by the applied charging strategy. 

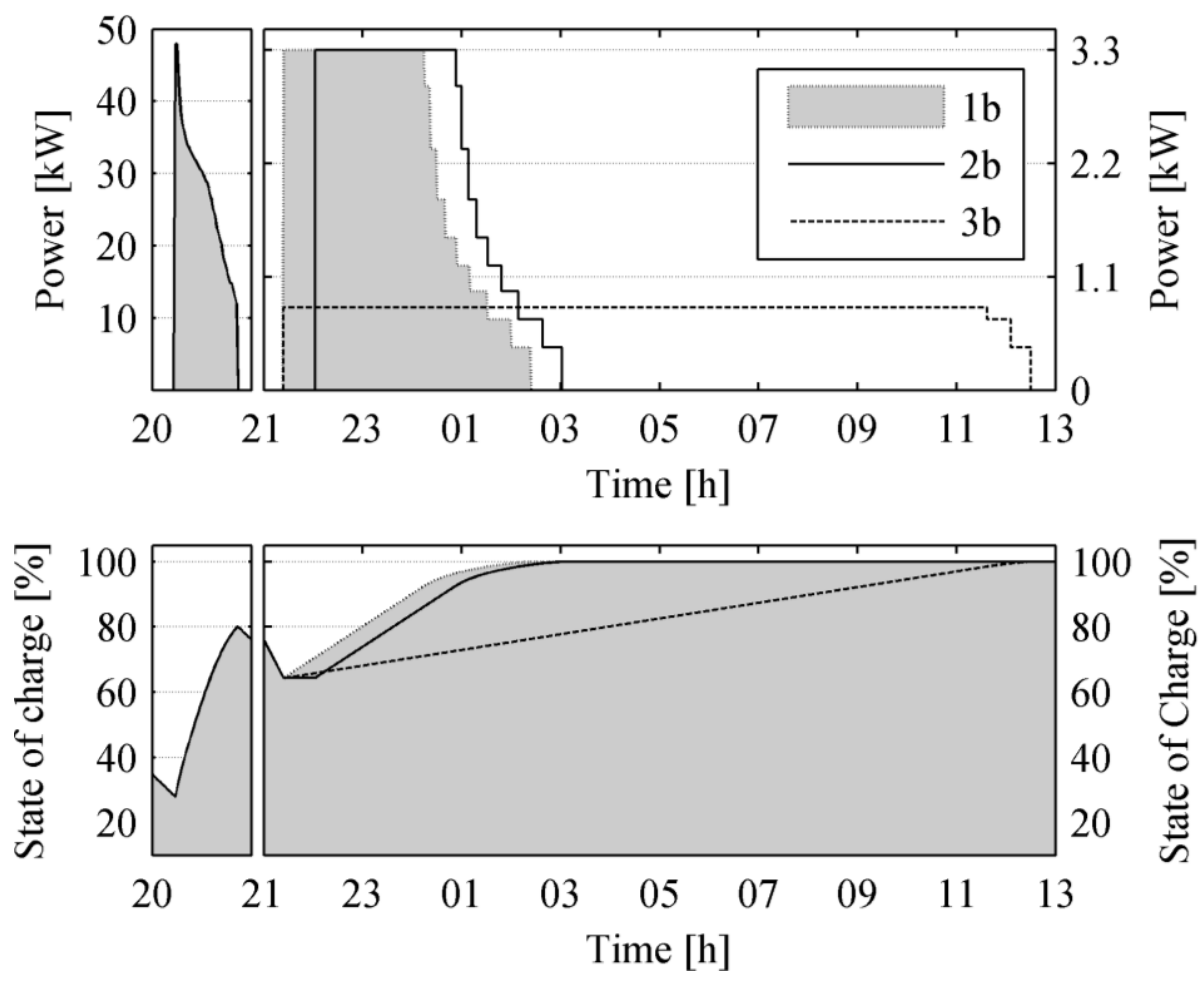

Figure 4. Fast (left) and slow (right) charging profiles (top), and the evolution of the state of charge (bottom).

To illustrate the aggregated grid impact of the EV charging behavior in detail, the profiles for a $40 \% \mathrm{EV}$ penetration rate (936 EVs) are illustrated in Figure 5, for a $12 \mathrm{~h}$ timespan. As can be seen, the residential grid impact differs significantly for the three cases. The highest residential charging peak occurs for $c=2 b$, which results in the highest MV feeder load. This is due to the synchronization effect that occurs at the start of the off-peak tariff period, which does not occur for $c=1 b$, because the distribution of the arrival at home of EVs. The lowest peak power occurs for $c=3 b$, resulting in the lowest MV feeder load of the three cases. This is due to the combination of the spread on the EV arrival times at home, the SOC when arriving at home, and the time until the next departure time. Therefore, there is a spread on the charging time and charging power, which significantly reduces the peak load, as can be seen in Figure 5.

The fast charging profiles are identical for $c=1 b$ and $c=3 b$, as the SOC for both cases is identical at the time of departure for each trip. As a consequence, their SOC profiles will be identical during driving, so there is an identical need for fast charging for both cases. The fast charging profile is different for $c=2 b$, but it has similar peak values, as the need for fast charging is only slightly higher, which can be seen when comparing the fast charge energy share of the different cases in Table 7. The fast charge peak load is significantly lower than the residential slow charging peak, because it only accounts for a small share of the charging actions. Therefore, the grid impact of the slow charging strategy is more significant than the presence of fast charging. 

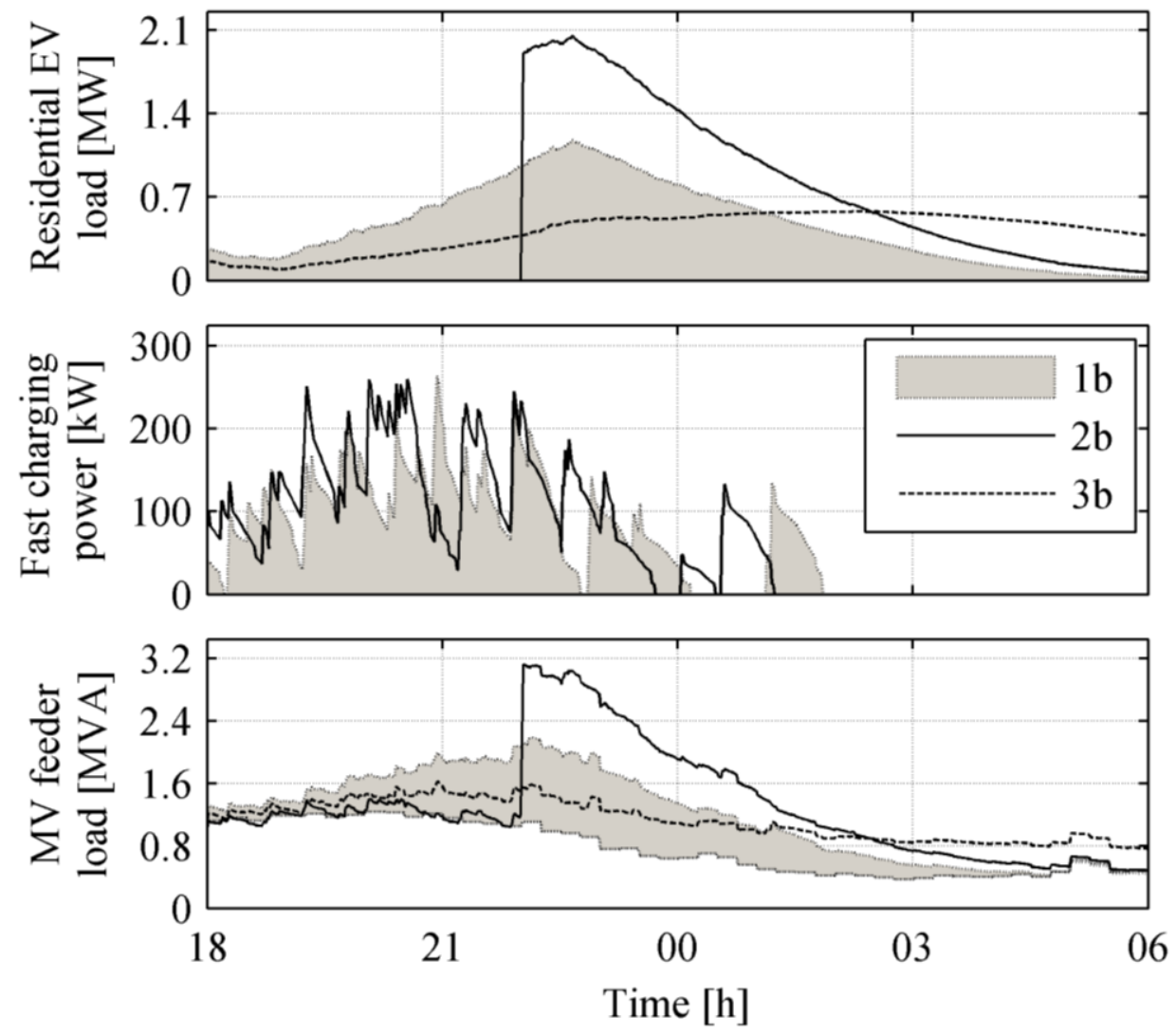

Figure 5. Load impact for a $40 \% \mathrm{EV}$ penetration rate. The white surface in the bottom figure represents the non-EV residential load.

\subsection{EV Hosting Capacity}

To illustrate the impact of the EV load on the grid voltages in detail, the per-phase nodal voltages are illustrated in Figure 6 for a one-hour time period between $19 \mathrm{~h}$ and $20 \mathrm{~h}$, for $c=1 b$, with a $40 \%$ EV penetration rate. The per-phase MV feeder load and the resulting per-phase voltages at the 9th node of the MV feeder are shown. Also, the per-phase LV grid load at the 9th MV node are illustrated, as well as the nodal voltages at the LV node the farthest away from the MV/LV transformer are illustrated, i.e., node 62 of feeder topology LV3 that is connected to the 9th MV node. In this way, the per-phase loads and voltages at the MV and LV level are illustrated in detail for a one-hour timespan when uncoordinated EV charging occurs.

As can be seen, there are notable differences in load of the phases. This is due to the fact that the households have a single-phase grid connection, which a common type of residential grid connection in Flanders. As a result, there is unbalance in the instantaneous grid load, due to the differences in household power consumption profiles. The modeled EV chargers are also single-phase, causing unbalance as well. It is seen that even on the aggregated MV level, this unbalance in the per-phase loads is not negligible. Also, the PV installation are not evenly spread over the three phases, resulting in an unbalanced PV power injection. The fast chargers each have a three-phase grid connection, therefore they act as a balanced grid load.

The unbalanced loads result in noticeable differences in the nodal phase voltages. The difference in the per-phase voltage magnitudes exceeds $0.01 \mathrm{pu}$ at the 9 th node of the MV feeder, and they exceed 
$0.05 \mathrm{pu}$ at the 62 th node of the LV feeder. This illustrates the added value of performing an unbalanced load flow (as will be discussed below), otherwise the voltage deviations are underestimated when assuming a balanced situation at the MV/LV interface. As a result, the EV hosting capacity would be overestimated.

\section{$\circ$ Phase A $\nabla$ Phase B $\square$ Phase C}
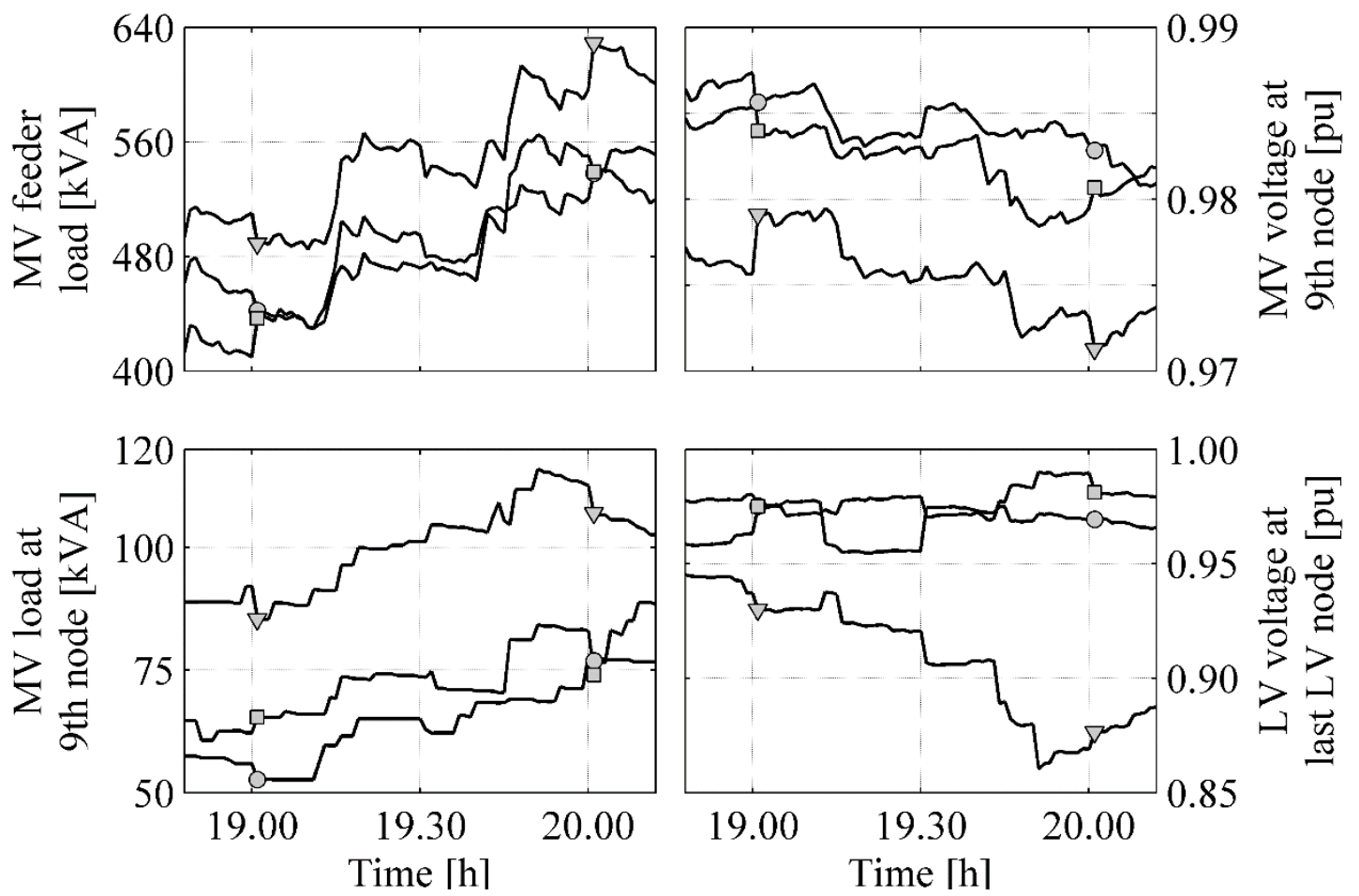

Figure 6. Per-phase load profiles (left) and voltage magnitudes (right), at the last MV node (top) and the last LV node (bottom), for case $1 \mathrm{~b}$ with a $40 \% \mathrm{EV}$ penetration rate.

For each charging case $c$, the EV hosting capacity is calculated as the maximum EV penetration rate $R_{\mathrm{MAX}}^{\mathrm{EV}}$ that can be accepted, while not exceeding the grid voltage constraints and the feeder current constraints, as discussed in Section 2.1. The resulting EV hosting capacity for the charging cases are summarized in Table 8. For each case considered here, the voltage magnitude constraints, i.e., Equations (1) and (2), are the most stringent ones. As can be seen, the cases without fast charging result in an equal or higher $R_{\mathrm{MAX}}^{\mathrm{EV}}$ than the cases with fast charging. However, the differences between the cases with and without fast charging are limited to only 10 percentage points, which is equal to only 1 step of increase in the EV penetration rate. This is due to the limited share of fast charging in the charging behavior of the EVs, while residential charging accounts for the vast majority of charging actions.

Table 8. EV hosting capacity [\%].

\begin{tabular}{ccccccc}
\hline Case & 1a & 1b & 2a & 2b & 3a & 3b \\
\hline $\boldsymbol{R}_{\mathbf{M A X}}^{\mathbf{E V}}$ & 80 & 70 & 50 & 40 & 100 & 100 \\
\hline
\end{tabular}

$R_{\mathrm{MAX}}^{\mathrm{EV}}$ is more influenced by the slow charging strategies than whether or not fast charging occurs, as differences up to 60 percentage points occur between the different slow charging cases. 
These results show that the additional grid impact due to the presence of fast charging can easily be compensated for by the implementation of a more grid-friendly residential charging strategy. For instance, by incentivizing EV users to start charging immediately when arriving at home $(c=1 a / 1 b)$ instead of waiting until the off-peak tariff period starts $(c=2 a / 2 b)$, a significantly higher $R_{\mathrm{MAX}}^{\mathrm{EV}}$, even if fast charging is possible. This is due to the synchronization effect of EV charging at the start of the off-peak tariff period for $c=2 a / 2 b$, which creates a peak in the power demand. This power peak results in a voltage drop that negates the beneficial effect of shifting the charging load away from the time of the residential peak demand. An even higher $R_{\mathrm{MAX}}^{\mathrm{EV}}$ is possible when EV-based peak shaving is applied $(c=3 a / 3 b)$, as it allows for a $100 \% \mathrm{EV}$ penetration rate for the scenario discussed here, whether or not fast charging occurs. Therefore, when the local EV penetration rate increases to significant levels, the EV users should be incentivized to charge their EVs in a more grid-friendly manner, as this can allow for a substantially higher EV hosting capacity with the same grid infrastructure.

\subsection{Fast Charging Requirements}

The fast charging power peak and the one percent peak (OPP) value are illustrated in Figure 7 for $\mathrm{EV}$ penetration rates up to $R_{\mathrm{MAX}}^{\mathrm{EV}}$. The OPP is the value above which only $1 \%$ of the values are situated. For $c=1 b$ and $c=3 b$, the values are identical for fast charging, but the values for penetration rates above $70 \%$ are only applicable for $c=3 b$, as this is the $R_{\mathrm{MAX}}^{\mathrm{EV}}$ for $c=1 b$. For $c=2 b$, the values are only marginally different from those of the other two cases, as the fast charging requirements very similar. The OPP for fast charging power is significantly smaller than the peak value, which is related to the fact that the fast charging power profile for each EV, as illustrated in Figure 3, only draws its maximal power for a short period and it quickly declines as the SOC increases. Therefore, the MV/LV transformer that connects the fast charging station to the MV grid, might be sized for a power rating smaller than the expected peak value, as this value only occurs for a very short time.

The peak value and the OPP value for the occupation of fast chargers is also illustrated in Figure 7. As can be seen, 19 fast chargers are needed to cover the requirements at all times. However, for $99 \%$ of time, 16 fast chargers are sufficient. Therefore, it might be more efficient to allow for a limited waiting time during these peak situations, and thereby avoiding the investment in additional chargers that are only useful for $1 \%$ of time. Furthermore, this would reduce the fast charging power peak, which would lower the grid impact of the fast charging infrastructure. These results are in line with [40], where the number of fast chargers is reduced with $40 \%$, which resulted in waiting times below $10 \mathrm{~min}$ for $99.7 \%$ of time.

For an increasing EV penetration rate, i.e., from $10 \%$ to $100 \%$ for $c=3 b$, the ratio of fast chargers to EVs lowers significantly: from $3 \%$ to $0.9 \%$ for the peak value, and from $1.7 \%$ to $0.7 \%$ for the OPP. This means that there is a need for one fast charger for each 111-142 EVs, when there is a sufficiently high amount of EVs on the roads. This number can be compared to the ratio of fuel stations per car in Europe, which varies from 1/1500 (Luxembourg) to 1/3500 (Germany) stations per vehicle [59]. Thus, for a fast charging infrastructure with the same spatial spreading as the current fueling infrastructure and a $100 \% \mathrm{EV}$ penetration rate, the fast charging infrastructure would consist out of stations with on average 11-25 fast chargers to cover the OPP, or with on average 14-32 fast chargers to cover the peak value. 


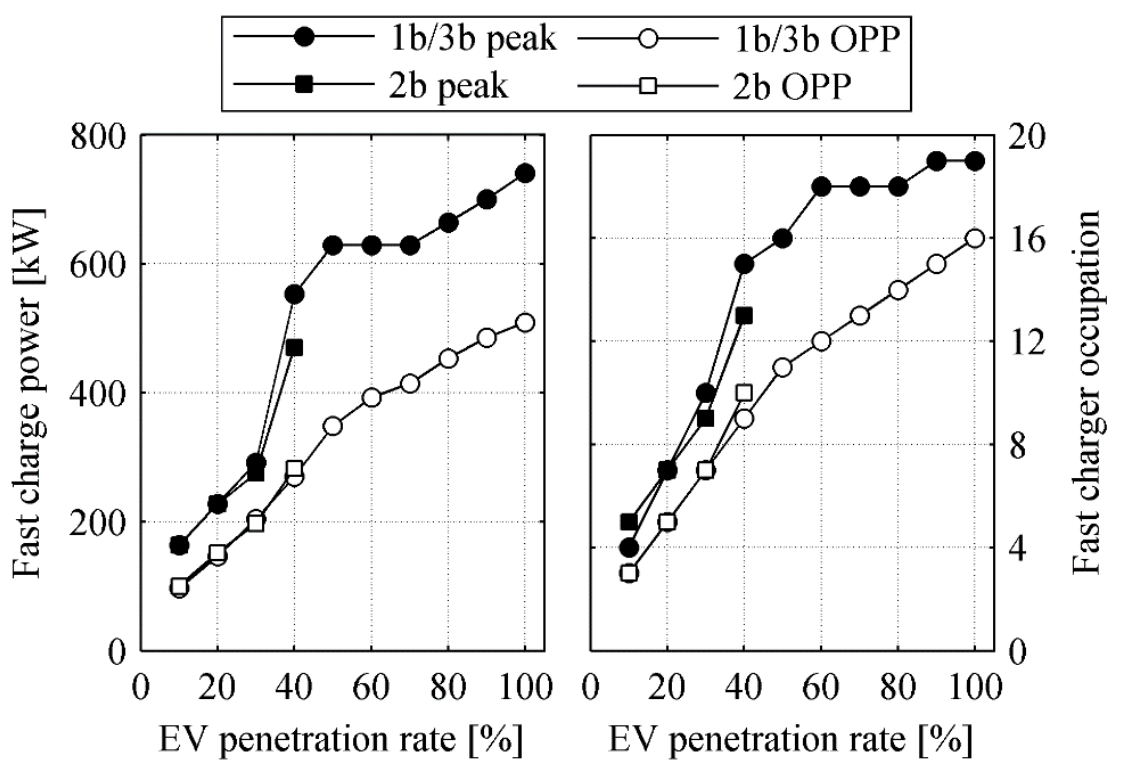

Figure 7. Peak values and one percent peak (OPP) for the fast charging load (left); and fast charger occupation (right).

An increase in EV battery capacity would decrease the ratio of fast chargers to EVs significantly, because the share of fast charging increases significantly when the EV battery increases, as discussed in Section 3.1. For the cases discussed here, a doubling of the EV battery capacities would reduce the peak value and the OPP value for the ratio to $0.4 \%$ and $0.3 \%$, for a $100 \% \mathrm{EV}$ penetration rate. The resulting fast charging infrastructure would consist out of stations with on average 5-11 fast chargers to cover the OPP, or on average 6-14 fast chargers to cover the peak value. These results show that the fast charging infrastructure needs to be extensive, even though fast charging only account for a minority of the charging actions. This is due to the fact that a fast charger fuels a vehicle more slowly than a fuel pump.

\subsection{Peak Load}

The MV distribution feeder peak load, and the highest MV/LV residential grid transformer load are illustrated in Figure 8. As can be seen, the presence of fast charging reduces the LV residential peak load, but only slightly, as the presence of fast charging only accounts for a limited amount of the charging energy. Conversely, the presence of fast charging increases the peak load on the MV feeder, as this is where the fast charging infrastructure is connected to the grid. These opposing trends show how the presence of fast charging substitutes a fraction of the home charging actions. However, the difference in grid impact between the three slow charging cases is substantially larger than the difference between the situation with or without fast charging. Therefore, the increased grid impact of fast charging can be mitigated in an effective manner by implementing a grid-friendly slow charging strategy.

For $c=1 a / 1 b$ and $c=2 a / 2 b$, the LV residential peak loads are approximately the double at $R_{\mathrm{MAX}}^{\mathrm{EV}}$, compared to the case without EVs. The peak load is above $100 \%$ for $c=1 a$ and $c=2 a / 2 b$, at the higher EV penetration rates. This means that at least one of the 9 residential grid MV/LV transformers is loaded above its rated power. It must be assessed if the increase in transformer ageing 
is acceptable, or if a transformer upgrade is required. For $c=3 a / 3 b$, the peak load increases to a smaller degree, because the EVs on average charge at a significantly lower effective power rating. As a result, the transformer peak load stays well below the rated power for $c=3 a / 3 b$. The initial drop in the MV feeder load is due an initial reduction in load unbalance, when the low amount of EV charging load reduces the load unbalance on the grid.

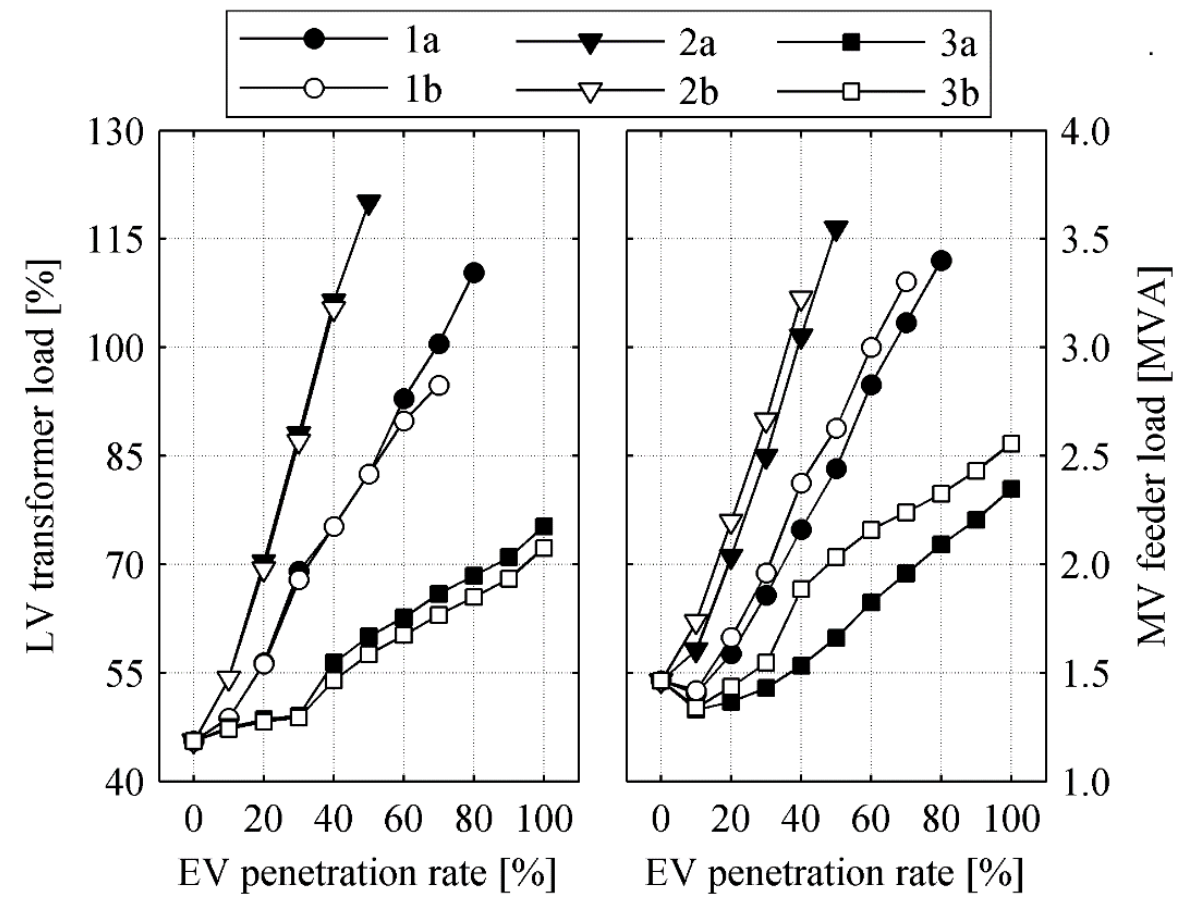

Figure 8. Highest MV/LV transformer peak load (left) and MV feeder peak load (right).

\section{Conclusions}

The distribution grid impact of EV charging is expected to be far more sensitive to the applied residential slow charging strategy, than to the presence or absence of fast charging. For a given residential slow charging strategy, the presence of fast charging decreases the EV hosting capacity with 10 percentage points or less. A more grid-friendly residential slow charging strategy increases the EV hosting capacity much more than the presence of fast charging decreases it. This is because EV charging at home accounts for the vast majority of EV charging, due to the long standstill times there. Fast charging only accounts for a low share of the EV charging energy, which even decreases further if EV battery capacities increase. As a result, fast charging stations have a limited impact on the medium voltage level, because the load increase is limited, compared to the load increase caused by residential slow charging. However, despite the limited share in the charging energy, fast charging infrastructure is indispensable to allow the vehicle fleet to drive close to purely electrically.

The choice of the slow charging strategy at home strongly influences the EV hosting capacity, which varies from $40 \%$ up to $100 \%$. The highest hosting capacity occurs when EV-based peak shaving is implemented, both with and without fast charging, as for most of the time the effective charging power will be significantly lower than the rated power. This is due to the typical long standstill times at home and the typical low daily driven distances. Therefore, EV-based peak shaving significantly reduces the distribution grid impact, compared to the other two strategies. The lowest EV hosting 
capacity occurs for off-peak residential charging, due to the synchronization of the residential charging actions at the start of the off-peak period. This synchronization of EV load creates a peak that is higher than for the other cases. Therefore, distribution grid operators should consider adapting the peak/off-peak tariff scheme for households with an EV, when a significant local EV penetration rate occurs. By incentivizing more grid-friendly EV charging strategies, a higher EV penetration rate can be accepted without the need to invest in grid infrastructure.

Fast charging stations are fundamentally different from refueling stations for conventional vehicles. The latter are responsible for all of the refueling needs, while the former are only responsible for a fraction of the charging needs. However, because the charging actions take much more time than for conventional refueling, the infrastructure will still be substantial. Furthermore, the fast chargers have a three-phase power electronic interface that is permanently connected to the grid. Therefore, this widespread infrastructure of permanently grid-connected power electronic interfaces offers possibilities to supply grid services, even without the presence of stationary energy storage, e.g., active filtering, reactive power support, and grid balancing. Such services might be useful, as voltage deviations are observed at the MV grid level, due to the load situation of the grid, but also due to load unbalance.

\section{Acknowledgments}

Niels Leemput has a Ph.D. grant of the Institute for the Promotion of Innovation through Science and Technology in Flanders (IWT-Vlaanderen). Niels Leemput and Juan Van Roy are enrolled in the Ph.D. School of EIT-KIC InnoEnergy. KU Leuven is a partner of EnergyVille, Dennenstraat 7, 3600 Genk, Belgium.

\section{Author Contributions}

N.L., P.O.-R. and A.S. conceived and designed the experiments; N.L. performed the simulations; N.L., P.O.-R. and A.S. analyzed the data; N.L., F.G., J.V.R. and J.D. contributed materials and analysis tools; N.L. wrote the paper.

\section{Conflicts of Interest}

The authors declare no conflict of interest.

\section{References}

1. Bruninga, R.; Sorensen, J.A.T. Charging EVs efficiently now while waiting for the smart grid. In Proceedings of the IEEE Green Technologies Conferences, Denver, CO, USA, 4-5 April 2013; pp. 1-7.

2. Leemput, N.; van Roy, J.; Geth, F.; Driesen, J.; de Breucker, S. Grid and fleet impact mapping of EV charge opportunities. In Data Science and Simulation in Transportation Research; Janssens, D., Ed.; IGI Global: Hershey, PA, USA, 2013; pp. 364-390.

3. Electric Vehicle Conductive Charging System-Part 1: General Requirements; IEC Standard 61851-1; International Electrotechnical Commission: Geneva, Switzerland, 2010. 
4. Schneider Electric. Connection System on the Recharging Spot: A Key Element for Electric Vehicles. Available online: http://www.evplugalliance.org/en/doc/ (accessed on 8 December 2014).

5. Fast Charging along the Highway. Available online: http://www.fastned.nl/en (accessed on 8 December 2014).

6. Supercharger. Available online: http://www.teslamotors.com/supercharger (accessed on 8 December 2014).

7. Clement-Nyns, K.; Haesen, E.; Driesen, J. The impact of charging plug-in hybrid electric vehicles on a residential distribution grid. IEEE Trans. Power Syst. 2010, 25, 371-380.

8. Leemput, N.; van Roy, J.; Geth, F.; Tant, P.; Claessens, B.; Driesen, J. Comparative analysis of coordination strategies for electric vehicles. In Proceedings of the 2011 IEEE PES ISGT Europe, Manchester, UK, 5-7 December 2011; pp. 1-8.

9. Electric Car Charging: Electric Vehicle Charging Points in Ireland. Available online: http://www.esb.ie/electric-cars/electric-car-charging.jsp (accessed on 8 December 2014).

10. Kempton, W.; Tomić, J. Vehicle-to-grid power implementation: From stabilizing the grid to supporting large-scale renewable energy. J. Power Sources 2005, 144, 280-294.

11. Saber, A.Y.; Venayagamoorthy, G.K. Plug-in vehicles and renewable energy sources for cost and emission reductions. IEEE Trans. Ind. Electron. 2011, 4, 1229-1238.

12. Gallus, M.D.; la Fauci, R.; Andersson, G. Investigating PHEV wind balancing capabilities using heuristics and model predictive control. In Proceedings of the 2010 IEEE PES General Meeting, Minneapolis, MN, USA, 25-29 July 2010; pp. 1-8.

13. Tran-Quoc, T.; Braun, M.; Marti, J.; Kieny, C.; Hadjsaid, N.; Bacha, S. Using control capabilities of DER to participate in distribution system operation. In Proceedings of the 2007 IEEE PowerTech, Lausanne, Switzerland, 1-5 July 2007; pp. 561-566.

14. Sekyung, H.; Soohee, H.; Sezaki, K. Development of an optimal vehicle-to-grid aggregator for frequency regulation. IEEE Trans. Smart Grid 2010, 1, 65-72.

15. Vandael, S.; de Craemer, K.; Boucké, N.; Holvoet, T.; Deconinck, G. Decentralized coordination of plug-in hybrid vehicles for imbalance reduction in a Smart Grid. In Proceedings of the 10th International Conferences on Autonomous Agents and Multiagent System, Taipei, Taiwan, 2-6 May 2011; pp. 803-810.

16. Acha, S.; Green, T.C.; Shah, N. Optimal charging strategies of electric vehicles in the UK power market. In Proceedings of the 2011 IEEE PES ISGT, Anaheim, PA, USA, 17-19 January 2011; pp. $1-8$.

17. Rotering, N.; Ilic, M. Optimal charge control of plug-in hybrid electric vehicles in deregulated electricity markets. IEEE Trans. Power Syst. 2010, 26, 1021-1029.

18. Doostizadeh, M.; Khanabadi, M.; Esmaeilian, A.; Mohseninezhad, M. Optimal energy management of a retailer with smart metering and plug-in hybrid electric vehicle. In Proceedings of the 10th International Conferences on Environment and Electrical Engineering, Rome, Italy, 8-11 May 2011; pp. 1-5.

19. Lyon, T.P.; Michelin, M.; Jongejan, A.; Leahy, T. Is "smart charging" policy for electric vehicles worthwhile? Energy Policy 2012, 41, 259-268. 
20. Leemput, N.; Geth, F.; Claessens, B.; van Roy, J.; Ponnette, R.; Driesen, J. A case study of coordinated electric vehicle charging for peak shaving on a low voltage grid. In Proceedings of the 2012 IEEE PES ISGT Europe, Berlin, Germany, 14-17 October 2012; pp. 1-7.

21. Sortomme, E.; Hindi, M.M.; MacPherson, S.D.J.; Venkata, S.S. Coordinated charging of plug-in hybrid electric vehicles to minimize distribution system losses. IEEE Trans. Smart Grid 2011, 2 , 198-205.

22. Shao, S.; Zhang, T.; Pipattanasomporn, M.; Rahman, S. Impact of TOU rates on distribution load shapes in a smart grid with PHEV penetration. In Proceedings of the 2010 IEEE PES Transmission and Distribution Conference and Exposition, New Orleans, LA, USA, 19-22 April 2010; pp. 1-6.

23. Vandael, S.; Claessens, B.; Hommelberg, M.; Holvoet, T.; Deconinck, G. A scalable three-step approach for demand side management of plug-in hybrid vehicles. IEEE Trans. Smart Grid 2013, 4, 720-728.

24. De Craemer, K.; Vandael, S.; Claessens, B.; Deconinck, G. An event-driven dual coordination mechanism for demand side management of PHEVs. IEEE Trans. Smart Grid 2014, 5, 751-760.

25. Richardson, P.; Flynn, D.; Keane, A. Local versus centralized charging strategies for electric vehicles in low voltage distribution systems. IEEE Trans. Smart Grid 2012, 3, 1020-1028.

26. Hajimiragha, A.; Cañizares, C.A.; Fowler, M.W.; Elkamel, A. Optimal transition to plug-in hybrid electric vehicles in Ontario, Canada, considering the electricity-grid limitations. IEEE Trans. Ind. Electron. 2010, 57, 690-701.

27. Schneider, K.P.; Gerkensmeyer, C.E.; Kintner-Meyer, M.C.W.; Fletcher, R. Impact assessment of plug-in hybrid vehicles on pacific northwest distribution systems. In Proceedings of the 2008 IEEE PES General Meeting, Pittsburg, PA, USA, 20-24 July 2008; pp. 1-6.

28. Leemput, N.; Geth, F.; van Roy, J.; Delnooz, A.; Büscher, J.; Driesen, J. Impact of electric vehicle on-board single-phase charging strategies on a Flemish residential grid. IEEE Trans. Smart Grid 2014, 5, 1815-1822.

29. Schroeder, A.; Traber, T. The economics of fast charging infrastructure for electric vehicles. Energy Policy 2012, 43, 136-144.

30. Li, Z.; Ouyang, M. The pricing of charging for electric vehicles in China-Dilemma and solution. Energy 2011, 36, 5765-5778.

31. Bae, S.; Kwasinski, A. Spatial and temporal model of electric vehicle charging demand. IEEE Trans. Smart Grid 2012, 3, 394-403.

32. Yang, S.N.; Cheng, W.S.; Hsu, Y.C.; Gan, C.H.; Lin, Y.B. Charge scheduling of electric vehicles in highways. Math. Comput. Model. 2013, 57, 2873-2882.

33. Coninckx, C.; Claes, R.; Vandael, S.; Leemput, N.; Holvoet, T.; Deconinck, G. Anticipatory coordination of electric vehicle allocation to fast charging infrastructure. In Proceedings of the 12th International Conferences on Practical Applications of Agents and Multi-Agent Systems, Salamanca, Spain, 4-6 June 2014; pp. 1-12.

34. Etezadi-Amoli, M.; Choma, K.; Stefani, J. Rapid-charge electric-vehicle stations. IEEE Trans. Power Deliv. 2010, 25, 1883-1887. 
35. Yunus, K.; Zelaya-De La Parra, H.; Reza, M. Distribution grid impact of plug-in electric vehicles charging at fast charging stations using stochastic charging model. In Proceedings of the 2011 European Conferences Power Electronics and Application, Birmingham, UK, 30 August-1 September 2011; pp. 1937-1947.

36. Mauri, G.; Valsecchi, A. Fast charging stations for electric vehicle: The impact on the MV distribution grids of the Milan metropolitan area. In Proceedings of the IEEE Internationa Energy Conferences Exhibition, Florence, Italy, 9-12 September 2012; pp. 1055-1059.

37. Arancibia, A.; Strunz, K. Modeling of an electric vehicle charging station for fast DC charging. In Proceedings of the 2012 IEEE International Electric Vehicle Conferences, Greenville, CA, USA; 4-8 March 2012; pp. 1-6.

38. Aggeler, D.; Canales, F.; Zelaya-De La Parra, H.; Coccia, A.; Butcher, N.; Appeldoorn, O. Ultra-fast DC-charge infrastructures for EV-mobility and future smart grids. In Proceedings of the 2010 IEEE PES ISGT Europe, Gothenburg, Sweden, 11-13 October 2010; pp. 1-8.

39. Machiels, N.; Leemput, N.; Geth, F.; van Roy, J.; Buscher, J.; Driesen, J. Design criteria for electric vehicle fast charge infrastructure based on Flemish mobility behavior. IEEE Trans. Smart Grid 2014, 5, 320-327.

40. Lacroix, B.; Calvas, R. Earthing Systems Worldwide and Evolutions; Technical paper ECT173; Schneider Electric: Rueil-Malmaison, France, 1995.

41. Cables for Underground Construction, Full Synthetic Insulation and Fortified Cloak (Type $1 \mathrm{kV}$ ); NBN Standard C 33-322; Bureau for Standardization: Brussels, Belgium, 1975.

42. Belmans, R.; Deconinck, G.; Driesen, J. Deel IV: Transformatoren. In Elektrische Energie; Deel 1; ACCO: Leuven, Belgium, 2010; pp. 269-270.

43. Gonzalez, C.; Weckx, S.; Efkarpidis, N.; Vingerhoets, P.; de Rybel, T.; Driesen, J. Constrained PV penetration level in LV distribution networks based on the voltage operational margin. In Proceedings of CIRED 22, Stockholm, Sweden, 10-13 June 2013; pp. 1-4.

44. Lehtonen, M. Fault management in electrical distribution systems. In Proceedings of the CIRED 1999, Nice, France, 1-4 June 1999.

45. Gonzalez-de Miguel, C.; de Rybel, T.; Driesen, J. Enhancing reliability in medium voltage distribution networks with directional fault passage indicators without voltage sensors. Acta Electrotech. 2013, 54, 73-80.

46. Nexans S.A. 6-36 kV Medium Voltage Underground Power Cables: XLPE Insulated Cables. Available online: http://www.nexans.be/Belgium/2013/Medium\%20Voltage\%20Underground\% 20Power\%20Cables\%20Catalogue.pdf (accessed on 8 December 2014).

47. Voltage Characteristics of Electricity Supplied by Public Electricity Networks; CENELEC Standard EN 50160; European Committee for Electrotechnical Standardization (CENELEC): Brussels, Belgium, 2010.

48. Labeeuw, W.; Deconinck, G. Residential electrical load model based on mixture model clustering and Markov models. IEEE Trans. Ind. Inform. 2013, 9, 1561-1569.

49. De Cijfers. Available online: http://www.ode.be/zonnestroom/de-cijfers (accessed on 8 December 2014).

50. Specific Technical Instructions for Decentralized Production Installations Working in Parallel with the Distribution Grid; Synergrid Standard C10/11 (Rev. 12); Synergrid: Brussels, Belgium, 2009. 
51. SMA Solar Technology AG. Sunny Boy 240. Available online: http://files.sma.de/dl/18925/ SB240-DEN1442web.pdf (accessed on 3 February 2015).

52. Van Roy, J.; Leemput, N.; de Breucker, S.; Geth, F.; Tant, P.; Driesen, J. An availability analysis and energy consumption model for a Flemish fleet of electric vehicles. In Proceedings of the European Electric Vehicle Congress, Brussels, Belgium, 26 May 2011; pp. 1-12.

53. Tant, J.; Geth, F.; Six, D.; Driesen, J. Multiobjective battery storage to improve PV integration in residential distribution grids. IEEE Trans. Sustain. Energy 2013, 4, 182-191.

54. Dogger, J.; Roossien, B.; Nieuwenhout, F. Characterization of Li-ion batteries for intelligent management of distributed grid-connected storage. IEEE Trans. Energy Convers. 2011, 26, 256-263.

55. Seljeseth, H.; Taxt, H.; Solvang, T. Measurements of network impact from electric vehicles during slow and fast charging. In Proceedings of the CIRED 2013, Stockholm, Sweden, 10-13 June 2013; pp. 1-4.

56. VREG. Available online: http://www.vreg.be/ (accessed on 8 December 2014).

57. Cheng, C.; Shirmohammadi, D. A three-phase power flow method for real-time distribution system analysis. IEEE Trans. Power Syst. 1995, 10, 671-679.

58. Duvall, M.; Knipping, E.; Alexendar, M.; Tonachel, L.; Clarc, C. Environmental Assessment of Plug-in Hybrid Electric Vehicles, Volume 1: Nationwide Greenhouse Gas Emissions; Technical Report 1015325; Electric Power Research Institute: Palo Alto, CA, USA, 2007.

59. Evolutie van het Aantal Tankstations. Available online: http://www.petrolfed.be/nl/ petroleumindustrie/economie/evolutie-van-het-aantal-tankstations (accessed on 8 December 2014).

(C) 2015 by the authors; licensee MDPI, Basel, Switzerland. This article is an open access article distributed under the terms and conditions of the Creative Commons Attribution license (http://creativecommons.org/licenses/by/4.0/). 